\title{
The Peculiarities of Gratitude Expression Use in the Foreign Language (on the Example of English)
}

\author{
Saltanat Meiramova1, Assem Kulzhanova² \\ ${ }^{1}$ International Cooperation and Multilingual Education Development Centre, Seifullin Kazakh Agrotechnical \\ University, Astana, Kazakhstan \\ ${ }^{2}$ Theory and Practice of Foreign Language Department, Gumilyov Eurasian National University, Astana, \\ Kazakhstan \\ Email: meiramovas@gmail.com
}

Received February 2015

\begin{abstract}
It is known that expressing gratitude is one of the most frequently occurring communicative acts in most languages in the world. According to Nofsinger [1999:29], thanking is a speech act, specifically classified under expressive, which are "expressions of the speaker's psychological state about something (an event, an object, a behaviour, or whatever)." Also, the general idea is that thanks maybe viewed as unimportant routine formulae. This paper attempts to investigate the linguistic and semantic characteristics of gratitude expressions' use in the English language by Kazakhstani EFL students of higher school. In addition, the paper tries to determine the impact of social factors on the way the gratitude is expressed and also show the importance of thankfulness when it is missing in situations in which it is expected. To do so, the practical analysis of gratitude expressions' use in oral speech has been done. Sixty people were selected from among students of Gumilyov Eurasian National University to collect data through a discourse completion task (DCT) adapted from Eisenstein and Bodman (1993). The results of the study show that the most frequently used gratitude expressions by Kazakhstani EFL students are expressions of happiness, thankfulness and best wishes in oral speech informal style.
\end{abstract}

\section{Keywords}

Gratitude, Expressing, Thanking, Impact, Discourse Completion Task, Kazakhstani EFL Students

\section{Introduction}

Verbal communication is one of the crucial human activities. Speaking the felicitous language in different situations is extremely important to successful communication. Therefore, interlocutors should take into account different elements of conversation. Gratitude as a fundamental element of verbal communication is examined by the authors of the present research work. The word gratitude is "derived from the Latin root gratia, meaning grace, graciousness, or gratefulness" [1]. According to Nofsinger, gratitude is a speech act, specifically classi- 
fied under expressives, which are "expressions of the speaker's psychological state about something (an event, an object, a behavior, or whatever)" [2]. Moreover, expression of gratitude has its own cultural identity. As for English verbal behavior, the expression of gratitude plays pivotal role in everyday interactions. Englishman it is one of the means to demonstrate mutual respect. The English proverb says "It's a good day when your thank your bag is full". The peculiarity of English communication is that a conversation between acquainted interlocutors is not limited by explicit gratitude. Generally, it is accompanied or even substituted by emotionally estimating lexis. For instance, it may be estimation of an object of appreciation or estimation of interlocutor, his qualities or actions. Sometimes emotional estimation is more important than explicit gratitude. In other words, to say "thank you" is less valuable than emotional estimation.

Commonly, EFL learners have difficulties with replying for the favour. From the authors' view of point this takes place because of the lack of intercultural communication. Failure to express gratitude acceptably can sometimes result in ruining the relationship of giver and receiver. In order to produce appropriate language, a person should be aware of pragmatic competence as well as the grammatical one. Crystal [3] as cited in [4] defined pragmatics as "the study of language from the point of view of the user, especially of the choices they make, the constraint they encounter in using language in social interaction and the effects of their use of language on other participants in the act of communication”. However, teachers of EFL in Kazakhstan not always accentuate pragmatic knowledge in a classroom. Hence, misunderstanding and pragmatic failure take place. According to Thomas, pragmatic failure is the disability to comprehend what is meant by what is sent [5]. It plays pivotal role in foreign language acquisition. Thus, topicality of this paper is determined by the need of deep study of the gratitude expressions in the foreign language, particularly in English. Topicality of the research work is also specified by an active development of cross-cultural communication in Kazakhstan.

\section{Methodology}

\subsection{Participants}

The total population participating in this study consisted of 60 people who were selected from among students of L. N. Gumilyov Eurasian National University in Astana. They are both male (30) and female (30), aging from 20 to 22. The learners study English as a foreign language for 4 years.

\subsection{Instrumentation}

In order to collect data a discourse completion task (DCT) adapted from Eisenstein and Bodman was used [6]. A discourse completion task took 30 minutes to answer the questions. The authors of the study revised questions, modified and adapted to the Kazakhstani context, and formed the final discourse completion task (Appendix 1). The participants were supposed to respond to 10 different situations. In each situation someone had done something for participant or requested a favor, so the situation required the participants to feel obliged or grateful to the benefactor. The participants imagined themselves in real situation and responded based on their prompt reaction.

\subsection{Procedure}

The participants were engaged in the process of data collection in January, 2015. They received the questionnaire and imagined themselves in those situations. The participants wrote many words and sentences which they wanted to express their feelings towards the benefactor. As this paper attempts to determine an impact of social factors on expressing gratitude, these ten scenarios varied on the contextual factors of interlocutor familiarity and social status.

According to the collected data, the authors identified the strategy of gratitude used by the participants. So then the answers of the participants were coded based on the gratitude strategies taxonomy created by Cheng [7].

\subsection{Results and Discussion}

The participants enjoyed the questionnaire and thanked the authors of the study. The results show how Kazakhstani male and female people differ in the gratitude expressions. The frequency of gratitude strategies used 
by male participants is shown in Table 1. As for Kazakhstani female people, the results of the study are shown in Table 2. According to the results the most frequent responses among males and females are "thank you", "thank you very much" and "thanks". As the authors have noticed there is a difference in the use of the thanking strategy between Kazakhstani males and females. Thanking strategy was used 502 times: 204 times by males, 298-by females. Hence, Kazakhstani females often thank other people in order to be polite. On the second place in order of frequency of gratitude expression used both by males and females is positive feeling. The female participants use this strategy more frequently than males $(63>48$ times). The third strategy with higher frequency among females is apology (29 times), while males used it only 2 times. It means Kazakhstani females tend to use apology by stating the favor "I am sorry for the problem I made" (Appendix 1, question 6). However, in such situations Kazakhstani males prefer to use just thanking words or repayment strategy instead of the apologizer words. Thus, the repayment strategy was used 21 times by male participants, and 9 times by females. The results showed that males feel much indebted towards their hearers that's why they use more repayment strategies.

The DCT adapted in this study contains ten situations, two situations (Appendix 1, questions 2 and 10) involve higher social status of the addressee, five (Appendix 1, questions 4, 5, 6, 7 and 8) involve equal social status of the interlocutors, and three situations (Appendix 1, questions 1, 3, 9) involve lower social status of the addressee. The analysis of the collected data shows that social factors influence on the way of expressing gratitude

Table 1. Frequency of overall strategy use for Kazakhstani males.

\begin{tabular}{ccc}
\hline \multirow{2}{*}{ Type of gratitude strategy } & \multicolumn{2}{c}{ Frequency } \\
\cline { 2 - 3 } Thanking & Number & Percent (\%) \\
Appreciation & 204 & 69.15 \\
Repayment & 1 & 0.34 \\
Recognition of imposition & 21 & 7.12 \\
Apology & 3 & 1.02 \\
Positive feeling & 2 & 0.68 \\
Alerter & 48 & 16.27 \\
Other Expressions & 9 & 3.05 \\
Total & 7 & 2.37 \\
\hline
\end{tabular}

Table 2. Frequency of overall strategy use for Kazakhstani females.

\begin{tabular}{ccc}
\hline \multirow{2}{*}{ Type of gratitude strategy } & \multicolumn{2}{c}{ Frequency } \\
\cline { 2 - 3 } Thanking & Number & Percent (\%) \\
Appreciation & 298 & 70.45 \\
Repayment & 13 & 3.07 \\
Recognition of imposition & 9 & 2.13 \\
Apology & 2 & 0.47 \\
Positive feeling & 29 & 6.86 \\
Alerter & 63 & 14.89 \\
Other Expressions & 6 & 1.42 \\
Total & 3 & 0.71 \\
& 423 & 100 \\
\hline
\end{tabular}


as well as gender. For instance, at the situations 2 and 10 (Appendix 1) the most common strategy was using "Thank you" as a simple expression of gratitude and adding another strategy such as appreciation. Females were willing to express their gratitude to their hearers using appreciation strategies (13 times) instead of simple or elaborate thanking when they are going to express their gratitude to someone in higher status (Appendix 1, question 2, 10). Such phrases as "I appreciate the time you spent for me" and "I appreciate it!" were used by females. Many participants tried to use appropriate gratitude strategies. When the interlocutor had the same social status as the speaker, the participants used various strategies. For instance, the phrases "thanks", "you are the life safer", "you should not do that" and "I am sorry for that" were used by the participants. Thus, all types of gratitude strategies were used in situations when the speaker and the hearer had equal social status.

As for situations when the participants wanted to communicate with someone of lower social status, the participants used thanking strategy, appreciation. Phrases "thank you very much", "thank you for your help" and "I appreciate you" were used by the participants.

\section{Conclusions}

Taking into account the present study's findings we have got the conclusion, that Kazakhstani learners of English mostly use thanking and positive feeling strategy. Moreover, Kazakhstani male and female people differ in expressing gratitude. That is, female learners felt the necessity to thank and appreciate interlocutor more than males did. It might be caused by a number of factors such as their social status, cultural norms, and degree of politeness. The authors of the study have found that social factors have an impact on expressing gratitude. With people of higher and lower social status students are polite but limited in variety of strategies. Mostly, they use appreciation and thanking strategy. When the interlocutor has equal social status the participants are more talkative, used various types of gratitude expressions such as thanking, positive feeling, appreciation, apology, repayment, recognition and other expressions. Thus, this study provides the evidence that the expressions of gratitude in English in Kazakhstan depends on the various factors such as cultural differences, region, age, gender and social factors.

Some important pedagogical implications can be raised from the findings of this study. The present study also leaves some place for further investigation. Firstly, the future research will be done in other universities or colleges. Secondly, the developed thematic classification of gratitude expressions to be used in oral speech will be done.

\section{References}

[1] Emmons, R.A. and McCullough, M.E. (2003) The Psychology of Gratitude. Oxford University Press, New York, 377.

[2] Nofsinger, R.E. (1999) Everyday Conversation. Waveland Press, Prospect Heights, 29.

[3] Crystal, D. (1997) A Dictionary of Linguistics and Phonetics. 4th Edition, Oxford.

[4] Kasper, G. and Rose, K.R. (2001) Pragmatics in Language Teaching. Cambridge University Press. http://dx.doi.org/10.1017/CBO9781139524797.003

[5] Thomas, D. (1983) An Invitation to Grammar. Summer Institute of Linguistics, Mahidol University, Bangkok.

[6] Eisenstein, M. and Bodman, J. (1993) Expressing Gratitude in American English. In: Kasper, G. and Blum-Kulka, S., Eds., Interlanguage Pragmatics, Oxford University Press, Cary, 64-81.

[7] Cheng, L.Y. (2005) Changing Language Teaching through Language Testing: A Washback Study. Cambridge University Press, Cambridge. 


\section{Appendix 1}

Dear participant,

Thank you for participating in this survey. This study is intended to explore crosscultural and interlanguage speech behavior. The information you provide below will be used for this study only and will remain confidential. In the following section, please mark an ' $\mathrm{X}$ ' between the boxes corresponding to your response.

\section{Background information:}

Name: university:

Intended/completed Degree: BA MA PHD

Age:

Gender: Male Female

\section{Instruction}

The purpose of this study is to better understand speakers, as English learners, would respond to the given situations and how their responses are near to those of English native speakers. Some situations and their corresponding questions may sound odd or unfamiliar to you. Please be honest when completing the survey because your responses are valuable to this study.

You will find the following scenarios involve being placed in a situation where you may feel, to different degrees, obliged or grateful to someone who has done something for or requested of/from you. Please imagine yourself in each situation and respond accordingly based on your immediate reaction. If you feel that a specified situation does not warrant a response, please provide an explanation.

The questionnaire:

1. You board the bus, pay your money and take a seat near the front of the bus. Just before your stop, you guess that the driver is not going to stop. You move to the front, and ask the driver to stop and he stops.

You would say:

You would say nothing because:

2. You work for a large company, which is usually very busy. You send your manager a request for some days off. The vice-president of personnel calls you into his office. He tells you to sit down. You feel a little nervous, because you have only been working there for six months. The vice-president says, 'You're doing a good job. In fact, we are so pleased with you that I am going to give you a raise'.

You would say:

You would say nothing because:

3. In the supermarket, you ask the cashier to bag your groceries. He does this, and then turns to begin serving the next costumer. You pay and pick up your bags to leave.

You would say:

You would say nothing because:

4. At the table in a restaurant a friend says, you have something on your face.' You ask where. Your friend tells you. You rub your face and ask, 'Is it off?' your friend says that it is.

You would say:

You would say nothing because:

5. You find yourself in sudden need of money-2000 tenge. You mention this to a friend. Your friend immediately offers to lend it you. At first you say, 'Oh no, I didn't mean it as a request. I couldn't take it.'

Your friend says, 'Really, it’s all right. What are friends for?' Your friend insists again, and you take money.

You would say:

You would say nothing because:

6. You are studying in another city. Both you and your roommate work. You come home late from work and find that your roommate has done some work around the house that you had promised to do, but had not had a chance to do.

You would say:

You would say nothing because:

7. You have just gotten your hair cut in a new style, and you like it better than the old one. Your friend sees it 
and you ask him what he thinks. He says, 'Hey, you’ve got a new haircut. It looks nice'.

You would say:

You would say nothing because:

8. You share an apartment with a friend. You're both sitting and relaxing in the living room. You ask your friend to hand you the newspaper which is nearby. Your friend gives you the newspaper.

You would say: Thanks.

You would say nothing because:

9. You enter a parking garage. As the parking attendant gives you the parking voucher, you hand him the money and ask him about the empty space.

\section{You would say:}

You would say nothing because:

10. You have been invited to the home of a rather new friend. You have dinner with him and his family and a few other friends of theirs. The food was great, and you really enjoyed the evening. As you leave, your hosts accompany you to the door.

You would say:

You would say nothing because:

\section{Appendix 2}

\section{Gratitude strategies taxonomy}

1) Thanking: A. thanking comprising simple thanking by only using the word 'thank you'; B. thanking by stating the favor (thank you for your help, and thank you for your notice exemplify this sub-strategy); C. thanking and mentioning the imposition caused by the favor (Thank you for helping me cleaning the room)

2) Appreciation: A. using the word 'appreciate' (e.g. I appreciate it!); B. using the word 'appreciate' and mentioning the imposition caused by the favor (e.g. I appreciate the time you spent for me)

3) Repayment: A. offering services, food... (next time is my turn); B. feeling indebted (I owe you one); C. promising future self-improvement (it won't happen again)

4) Recognition of imposition: A. by acknowledging the imposition (exemplified by statements such as I know you are not allowed to give me extra time); B. stating or diminishing the need for the favor (you shouldn't do that)

5) Apology: A. using the apologizer words (I am sorry); B. using apology by stating the favor (I am sorry for the problem I made); C. expressing embarrassment (I feel embarrassed); D. criticizing oneself (I am such a fool...)

6) Positive feeling: A. expressing positive reaction to a person (You are a life saver); B. expressing positive feeling to action (such as this book was really helpful)

7) Other Expressions that do not belong to the mentioned strategies are categorized as other strategies comprising: A. here statements (here you are); B. small talk; C. leave taking (good bye, have a nice day); D. Joking

8) Alerter by using titles and names, attention getter in addition to the other strategies forms the alerter strategy: A. attention getter (e.g. Hey, Hi, and Well); B. title (e.g. Dr., Professor! Sir!); C. name (e.g. John, Mary) 